\title{
Variation in plasma calcium analysis in primary care in Sweden - a multilevel analysis
}

\author{
Sofia Dalemo*t1,2, Per Hjerpe ${ }^{+2,3}$, Henrik Ohlsson³, Robert Eggertsen', Juan Merlo³ and Kristina Bengtsson Boström²
}

\begin{abstract}
Background: Primary hyperparathyroidism (pHPT) is a common disease that often remains undetected and causes severe disturbance especially in postmenopausal women. Therefore, national recommendations promoting early pHPT detection by plasma calcium (P-Ca) have been issued in Sweden. In this study we aimed to investigate variation of P-Ca analysis between physicians and health care centres (HCCs) in primary care in county of Skaraborg, Sweden.

Methods: In this cross sectional study of patients' records during 2005 we analysed records from 154629 patients attending 457 physicians at 24 HCCs. We used multilevel logistic regression analysis (MLRA) and adjusted for patient, physician and HCC characteristics. Differences were expressed as median odds ratio (MOR).

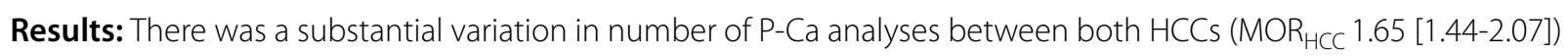
and physicians (MOR physician 1.95 [1.85-2.08]). The odds for a P-Ca analysis were lower for male patients (OR 0.80 [0.770.83]) and increased with the number of diagnoses (OR 25.8 [23.5-28.5]). Sex of the physician had no influence on P-Ca test ordering (OR 0.93 [0.78-1.09]). Physicians under education ordered most P-Ca analyses (OR 1.69 [1.35-2.24]) and locum least (OR 0.73 [0.57-0.94]). More of the variance was attributed to the physician level than the HCC level. Different mix of patients did not explain this variance between physicians. Theoretically, if a patient were able to change both GP and HCC, the odds of a P-Ca analysis would in median increase by 2.45. Including characteristics of the patients, physicians and HCCs in the MLRA model did not explain the variance.

Conclusions: The physician level was more important than the HCC level for the variation in P-Ca analysis, but further exploration of unidentified contextual factors is crucial for future monitoring of practice variation.
\end{abstract}

\section{Background}

Primary hyperparathyroidism (pHPT) is a common disease that often remains undetected and causes severe disturbance especially in postmenopausal women. Therefore, national recommendations promoting early pHPT detection by plasma calcium (P-Ca) have been issued in Sweden [1,2]. In this study we aimed to investigate variation of $\mathrm{P}-\mathrm{Ca}$ analysis between physicians and health care centres (HCCs).

pHPT is a potentially serious condition leading to increased morbidity and mortality from cardiovascular disease [3] and cancer [4]. Although mild disease might not increase the risk [5]. PHPT gives raised plasma cal-

*Correspondence: sofia.dalemo@vgregion.se

1 Dept of Public Health and Community Medicine/Primary Health Care, Sahlgrenska academy Gothenburg University, PO Box 454, SE-405 30

Gothenburg, Sweden

+ Contributed equally

Full list of author information is available at the end of the article cium (P-Ca) and because of the vague symptoms, pHPT is difficult to detect without an analysis of P-Ca.

Even though previous studies indicate that the frequency of P-Ca analyses differs between health care centres (HCC) [6] the understanding of the relative importance of the different levels (patients, physicians, HCCs) for these differences is limited. However, in a study from New Zealand where a defined clinical situation was presented to GPs, it was shown that inherent characteristics of the physicians more than the patients clinical situation determined which laboratory tests were ordered [7]. A study from the Netherlands, without patient characteristics, found a regional variation in laboratory testing and that factors at both the physician and HCC level influenced the inclination to order tests [8].

The aim of this study was to investigate the relative importance of the different levels in the health care organization for P-Ca analyses using the Skaraborg Primary 
Care Database (SPCD). Identification of factors contributing to the variation can be of relevance for planning interventions for an optimal frequency of $\mathrm{P}-\mathrm{Ca}$ analyses and for evaluating the national recommendations.

\section{Methods Study population}

Skaraborg is a rural area in Sweden and comprised 255 758 inhabitants in 2005. The public primary care is a part of the Västra Götaland region and serves $97 \%$ of the population ( $\mathrm{n}=247985)$. All the HCCs $(\mathrm{n}=24)$ use the same computerised medical record, ProfDoc Journal III (PDIII ProfDoc AB: Uppsala) facilitating data extraction. SPCD has been created containing encrypted data from patients and caregivers from all HCCs. The database contains patients' age, sex, diagnoses, laboratory analyses, and drug prescriptions. The HCCs' laboratory facilities are accredited by SWEDAC (the Swedish Board for Accreditation and Conformity Assessment). The validity of the information in the database has recently been audited and judged to be mostly appropriate but varying with type of diagnosis [9]. All 154629 individuals that attended any of the $24 \mathrm{HCCs}$ during 2005 are included in the analysis. The local ethics committee at Gothenburg University approved the study (255-09).

\section{Study procedure and assessment of variables}

The outcome variable was P-Ca analyses during 2005 (yes/no). Sex of the patient and P-Ca analyses during 2004 , were included as explanatory variables. We also selected ICD-10 coded diagnoses and symptoms associated with pHPT [10] . A risk score for a P-Ca analysis was created with stepwise logistic regression [11] based on age, concomitant diagnosis and drug treatment, in order to control for confounding factors. The risk score was divided in quintiles, patients with the lowest risk of $\mathrm{P}-\mathrm{Ca}$ analyses (group 1) were used as reference. The main characteristics included in the risk score are listed in Table 1 A more detailed description can be found in additional file 1.

The physicians were categorised according to sex and title. GP and locum were also dichotomised at 46 year. GPs, 46 years or older, were used as reference in the analysis. As only six doctors among house officers and preregistration house officers were above 45 years, they were not dichotomised.

The HCCs had different standardised group analyses, for instance analyses of electrolytes, hypertension check ups and diagnosing dementia, in which $\mathrm{P}-\mathrm{Ca}$ was included. We categorised HCCs as having none, 1-2, and $\geq 3$ standardised groups including P-Ca. The HCCs having no group analyses were used as reference.

\section{Statistical analysis}

We used multilevel logistic regression analysis (MLRA) to estimate the odds of patients being ordered a P-Ca analysis, as the data had a hierarchical structure (i.e., patients nested within physicians nested within HCCs) $[12,13]$. As one patient could attend several physicians and several HCCs, we used a multiple membership model (Figure 1) [14] . The weights were constructed according to number of visits to a certain physician/HCC during our study period.

We developed four consecutive models. Model A included the random parameters (physicians and HCCs), in order to partition the variance at different levels. Model B included the patient characteristics, model C the patient and physician characteristics and model D the patient, physician and HCC characteristics. In this way we could investigate whether the contextual characteristics explained the residual variation at the physician and HCC levels.

In the fixed-effects part of the MLRA, we calculated odds ratios (OR) and their 95\% credible intervals (95\% CI). In the random-effects part of the MLRA, we obtained the variance at the physician and HCC levels. In order to quantify the importance of the different levels in the analysis we calculated the median odds ratio (MOR) $[15,16]$. The MOR translates the variance into the widely used OR scale, and can thereby be directly compared with the ORs of individual or area variables. In very simple terms, the MOR could be interpreted as how much a patient's odds of being ordered a P-Ca analysis would (in median) increase if this patient moved to a physician/ $\mathrm{HCC}$ with higher odds of ordering a P-Ca analysis. A MOR of one indicates that there are no differences between physicians/HCCs in their odds of ordering P-Ca analysis. The larger the differences between physicians/ $\mathrm{HCCs}$ are, the larger the MOR will be. The $\mathrm{MOR}_{\text {physi- }}$ cian $+\mathrm{HCC}$ is applicable to patients that visited only one physician during the study period. Parameters were estimated by MCMC methods [17] in the MLwiN 2.02 software [18].

\section{Results}

Overall 5.8\% of the inhabitants in Skaraborg and 9\% of the patients (11\% of the women and $8 \%$ of the men) attending the $\mathrm{HCCs}$ had a $\mathrm{P}-\mathrm{Ca}$ analysis. The mean age of the patients with $\mathrm{P}-\mathrm{Ca}$ analysis was 62 years compared to 45 years for patients with no P-Ca analyses. At the different HCCs the number of standardised group analyses including $\mathrm{P}-\mathrm{Ca}$ analyses varied from zero to seven. The locums were most numerous shown in Table 2, but had short periods of attendance. 
Table 1: Examples of diagnoses with strong influence of the chance of having a plasma calcium analyses the risk score equation. Total number of patients 154629.

\begin{tabular}{|c|c|c|c|c|c|c|}
\hline Title & $\begin{array}{l}\text { All the positive diagnoses in the stepwise } \\
\text { regression }\end{array}$ & ICD-10 Codes & Odds ratio & $95 \%$ & $\mathrm{Cl}$ & $\begin{array}{r}\text { Number of } \mathrm{P}-\mathrm{Ca} \\
\text { analysis }\end{array}$ \\
\hline Neoplasms & Sarcoidosis & D86 & 8.4 & 3.3 & 21.4 & 21 \\
\hline \multirow[t]{2}{*}{ Endocrine disorders } & Nontoxic goitre & E04 & 3.1 & 2.2 & 4.5 & 177 \\
\hline & Other disorders of thyroid & E07 & 3.6 & 2.0 & 6.4 & 63 \\
\hline \multirow[t]{4}{*}{ Mental disorders } & Unspecified dementia & F03 & 2.5 & 2.0 & 3.0 & 523 \\
\hline & Depressive episode & F32 & 2.3 & 2.0 & 2.5 & 3196 \\
\hline & Anxiety disorder & F41.9 & 1.7 & 1.5 & 2.0 & 1438 \\
\hline & Nonorganic sleeping disorders & F51 & 1.5 & 1.3 & 1.7 & 1636 \\
\hline \multirow[t]{3}{*}{ Diseases of the circulatory system } & Essential hypertension & 110 & 1.8 & 1.7 & 1.9 & 12867 \\
\hline & Atrial fibrillation and flutter & 148 & 1.5 & 1.3 & 1.6 & 1792 \\
\hline & Heart failure & 150 & 1.7 & 1.5 & 1.9 & 1937 \\
\hline Diseases of the digestive system & Constipation & K59.0 & 1.7 & 1.4 & 2.0 & 730 \\
\hline \multirow{2}{*}{$\begin{array}{l}\text { Diseases of the musculoskeletal } \\
\text { system }\end{array}$} & Other artritis and rheumatism unspecified & M13 & 2.4 & 1.9 & 2.9 & 577 \\
\hline & Myalgia & M79.1 & 1.8 & 1.6 & 2.0 & 3749 \\
\hline \multirow[t]{4}{*}{ Symptoms } & $\begin{array}{l}\text { Abnormal blood-pressure reading, } \\
\text { without diagnosis }\end{array}$ & R03.0 & 2.7 & 2.3 & 3.3 & 580 \\
\hline & Polyuria & R35 & 2.0 & 1.5 & 2.7 & 355 \\
\hline & Headache & R51 & 2.5 & 2.2 & 2.9 & 1392 \\
\hline & Malaise and fatigue & R53 & 6.5 & 5.9 & 7.2 & 2261 \\
\hline \multirow[t]{2}{*}{ Contact with health services } & General medical examination & Z00.0 & 3.3 & 3.0 & 3.7 & 1911 \\
\hline & Worried well & $\mathrm{Z} 71.1$ & 2.5 & 2.2 & 2.8 & 1732 \\
\hline \multirow[t]{2}{*}{ Drug } & Calcium and vitamin D supplements & & 3.3 & 2.1 & 5.1 & 2938 \\
\hline & Thiazide diuretics & & 1.3 & 1.2 & 1.4 & 8305 \\
\hline
\end{tabular}

$\mathrm{P}-\mathrm{Ca}=$ plasma calcium

$95 \% \mathrm{Cl}=95 \%$ credible interval

\section{The multilevel model}

There was a substantial variation in number of $\mathrm{P}-\mathrm{Ca}$ analyses between HCCs and physicians. The four models used in the analyses are shown in Table 3. In model A the $\mathrm{MOR}_{\text {physician }+\mathrm{HCC}}$ indicated that for a patient changing both GP and HCC, to a GP and HCC with higher odds for a $\mathrm{P}-\mathrm{Ca}$ analysis, the odds would in median increase by 2.31. The physician level, $\mathrm{MOR}_{\text {physician }}=1.95$ (95\% CI: 1 . 85-2.08) contributed more than the HCC level, MOR $_{\mathrm{HCC}}$ $=1.65$ (95\% CI: 1.44-2.07). Figure 2 shows the residuals for physicians (Panel A) and for HCCs (Panel B) from the multilevel analysis.

\section{Model B, C and D}

Model B illustrates that female sex and increased number of diagnoses in the risk score was associated with higher propensity of a $\mathrm{P}-\mathrm{Ca}$ analysis However, the inclusion of other patient characteristics did not explain the variance at the physician or HCC level. Model C illustrates that house officers, preregistration house officer and younger GPs ordered more P-Ca analysis compared to older GPs. 


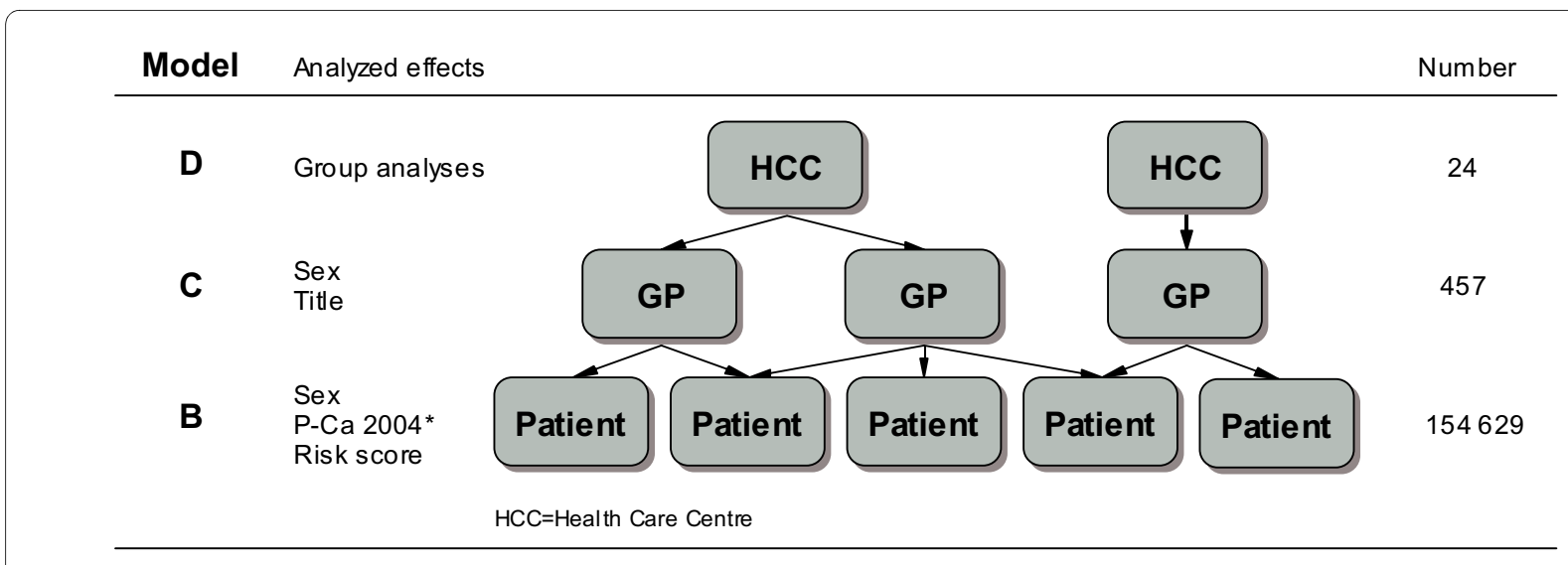

${ }^{*} \mathrm{P}-\mathrm{Ca}=$ plasma calcium

Figure 1 Multilevel model employed in plasma calcium analyses in primary care County of Skaraborg, Sweden. A three-level logistic regression model including health care centre (HCC), physician and patient levels. At each level the analysed effect and the number of elements are described. The arrows depict the nesting of patients within physicians and physicians within HCCs and crossing arrows the multiple memberships.

Locums, regardless of age, ordered fewer P-Ca analyses. There were no differences between male and female physicians. Inclusion of the physician characteristics did not explain the variance in model A. Model D illustrates that a high number of standardised group analyses were associated with a high number of P-Ca analyses. The inclusion of HCC characteristics did not explain the variance at the higher levels.

Including all explanatory variables and controlling for confounders, a patient changing both GP and HCC, from low to high odds for P-Ca analysis, the odds for a P-Ca analysis would in median increase by 2.5 times, $\mathrm{MOR}_{\text {physi- }}$ cian+HCC 2.45 .

\section{Discussion}

The main finding of this study was that the ordering of P$\mathrm{Ca}$ analyses was influenced by factors both at the physician and at the HCC level, with the physician level being more important than the HCC level. Theoretically, if a patient were able to change both GP and HCC, the odds of undergoing a $\mathrm{P}-\mathrm{Ca}$ analysis would in median increase

Table 2: Staffing of physicians at health care centres, characteristics of physicians and number of patients visits and frequency of plasma calcium analyses per title in the county of Skaraborg during 2005.

\begin{tabular}{|c|c|c|c|c|c|c|c|c|c|c|c|c|}
\hline & \multicolumn{2}{|c|}{ Physicians } & \multirow[b]{2}{*}{$\begin{array}{c}\text { Mean age } \\
\text { (year) }\end{array}$} & \multirow[b]{2}{*}{ SD } & \multirow[b]{2}{*}{$\begin{array}{c}\text { Median } \\
\text { age (year) }\end{array}$} & \multicolumn{4}{|c|}{ Physicians/HCC } & \multicolumn{3}{|c|}{ Patients visits } \\
\hline & $\begin{array}{r}\text { Total } \\
\text { number }\end{array}$ & $\begin{array}{l}\% \\
\text { women }\end{array}$ & & & & $\begin{array}{c}\text { Range } \\
\text { age (year) }\end{array}$ & Mean & SD & Median & Range & $\begin{array}{r}\text { Total } \\
\text { number }\end{array}$ & $\begin{array}{l}\text { With P-Ca } \\
\text { test } \%\end{array}$ \\
\hline $\begin{array}{l}\text { Preregistrati } \\
\text { on house } \\
\text { officer }\end{array}$ & 51 & 39 & 31 & 5.6 & 29 & $26-48$ & 2.2 & 2.7 & 1 & $0-7$ & 21424 & 11 \\
\hline $\begin{array}{l}\text { House } \\
\text { officer }\end{array}$ & 68 & 69 & 35 & 6.0 & 34 & $26-50$ & 3.0 & 1.9 & 3 & $0-9$ & 35712 & 11 \\
\hline $\mathrm{GP}<46$ year & 39 & 41 & 38 & 3.6 & 35 & $32-45$ & 1.7 & 1.4 & 2 & $0-4$ & 45491 & 10 \\
\hline $\mathrm{GP} \geq 46$ year & 85 & 32 & 55 & 8.6 & 52 & $46-67$ & 3.7 & 1.6 & 4 & $1-6$ & 92109 & 8 \\
\hline $\begin{array}{l}\text { Locum }<46 \\
\text { year }\end{array}$ & 112 & 17 & 36 & 5.4 & 36 & $27-45$ & 6.2 & 8.9 & 3 & $0-36$ & 23153 & 7 \\
\hline Total & 457 & 32 & 43 & 11.6 & 41 & $26-76$ & 23.3 & 18.1 & 18 & $2-85$ & 241529 & 9 \\
\hline
\end{tabular}

$\mathrm{GP}=$ general practioner

$\mathrm{HCC}=$ health care centre

$\mathrm{P}-\mathrm{Ca}=$ plasma calcium 
Table 3: Multi-level logistic regression analysis of plasma calcium analyses in primary care in the county of Skaraborg, Sweden

\begin{tabular}{|c|c|c|c|c|}
\hline & Model A & Model B & Model C & Model D \\
\hline Fixed effects & OR $(95 \% \mathrm{Cl})$ & OR $(95 \% \mathrm{Cl})$ & OR $(95 \% \mathrm{Cl})$ & OR $(95 \% \mathrm{Cl})$ \\
\hline \multicolumn{5}{|l|}{ Patient } \\
\hline Female & - & REF & REF & $R E F$ \\
\hline Male & - & $0,80(0,77-0,83)$ & $0,80(0,77-0,83)$ & $0,80(0,77-0,83)$ \\
\hline P-Ca test 2004 & - & $1,44(1,37-1,51)$ & $1,44(1,36-1,51)$ & $1,44(1,37-1,51)$ \\
\hline \multicolumn{5}{|l|}{ Risc score } \\
\hline Group 1 & - & REF & REF & REF \\
\hline Group 2 & - & $2,40(2,15-2,70)$ & $2,43(2,18-2,71)$ & $2,40(2,14-2,68)$ \\
\hline Group 3 & - & $4,51(4,08-5,04)$ & $4,56(4,13-5,06)$ & $4,51(4,08-4,97)$ \\
\hline Group 4 & - & $8,92(8,11-9,87)$ & $9,01(8,14-9,96)$ & $8,91(8,12-9,78)$ \\
\hline Group 5 & - & $25,8(23,5-28,5)$ & $26,1(23,7-28,8)$ & $25,8(23,5-28,4)$ \\
\hline \multicolumn{5}{|l|}{ Doctor } \\
\hline Female & - & - & REF & REF \\
\hline Male & - & - & $0,93(0,78-1,09)$ & $0,95(0,78-1,24)$ \\
\hline Preregistration house officer & - & - & $1,48(1,00-2,00)$ & $1,51(1,07-2,05)$ \\
\hline House officer & - & - & $1,69(1,35-2,24)$ & $1,57(1,26-2,09)$ \\
\hline $\mathrm{GP}<46$ year & - & - & $1,30(1,02-1,76)$ & $1,16(0,93-1,60)$ \\
\hline $\mathrm{GP} \geq 46$ year & - & - & REF & REF \\
\hline Locum $<46$ year & - & - & $0,84(0,61-1,08)$ & $0,78(0,58-1,03)$ \\
\hline Locum $\geq 46$ year & & & $0,73(0,57-0,94)$ & $0,69(0,51-0,89)$ \\
\hline \multicolumn{5}{|l|}{$\mathrm{HCC}$} \\
\hline \multicolumn{5}{|l|}{ Number groups include $\mathrm{P}-\mathrm{Ca}$} \\
\hline Group 1 & - & - & - & REF \\
\hline Group 2 & - & - & - & $2,59(1,56-3,53)$ \\
\hline Group 3 & - & - & - & $2,79(1,25-5,09)$ \\
\hline Random effects & Variance $(95 \% \mathrm{Cl})$ & Variance $(95 \% \mathrm{Cl})$ & Variance $(95 \% \mathrm{Cl})$ & Variance $(95 \% \mathrm{Cl})$ \\
\hline HCC (Intercept) & $0,28(0,15-0,58)$ & $0,32(0,16-0,67)$ & $0,32(0,18-0,66)$ & $0,36(0,16-0,80)$ \\
\hline $\mathrm{MOR}_{H C C}$ & $1,65(1,44-2,07)$ & $1,71(1,47-2,18)$ & $1,72(1,49-2,17)$ & $1,77(1,48-2,34)$ \\
\hline Physician (Intercept) & $0,49(0,41-0,59)$ & $0,59(0,50-0,71)$ & $0,52(0,43-0,62)$ & $0,52(0,43-0,63)$ \\
\hline $\mathrm{MOR}_{\text {Physician }}$ & $1,95(1,85-2,08)$ & $2,09(1,96-2,24)$ & $1,98(1,87-2,12)$ & $1,99(1,88-2,13)$ \\
\hline HCC and Physician (Intercept) & 0,77 & 0,91 & 0,84 & 0,88 \\
\hline $\mathrm{MOR}_{\text {HCC+Physician }}$ & 2,31 & 2,48 & 2,4 & 2,45 \\
\hline DIC & 89550 & 76438 & 76427 & 76427 \\
\hline
\end{tabular}

Figure in italics are significant at 0.05 level

$\mathrm{P}-\mathrm{Ca}=$ plasma calcium

$95 \% \mathrm{Cl}=95 \%$ credible interval

$\mathrm{MOR}=$ median odds ratio. $\mathrm{OR}=$ odds ratio 


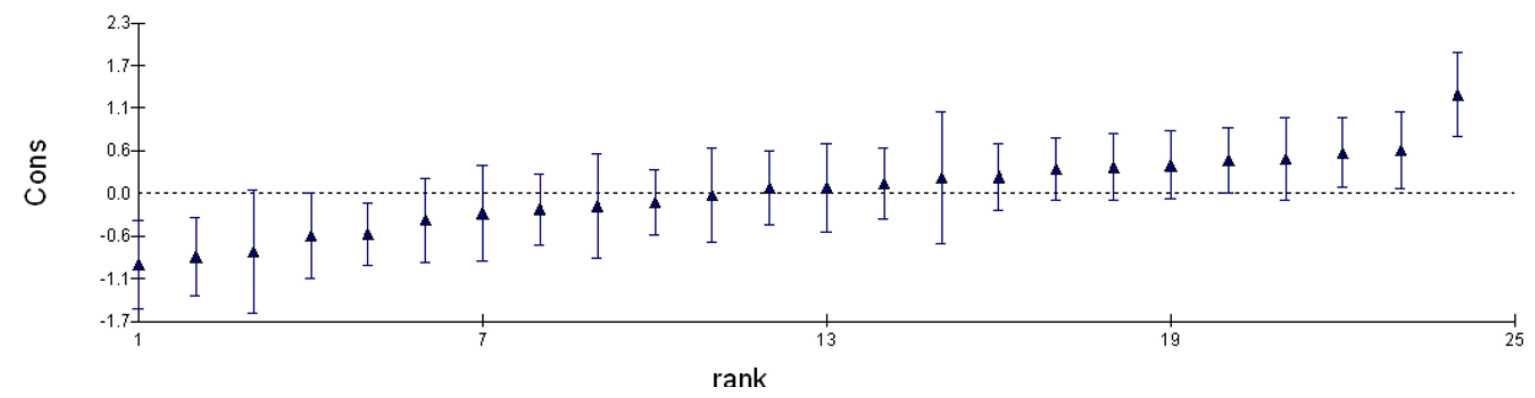

B

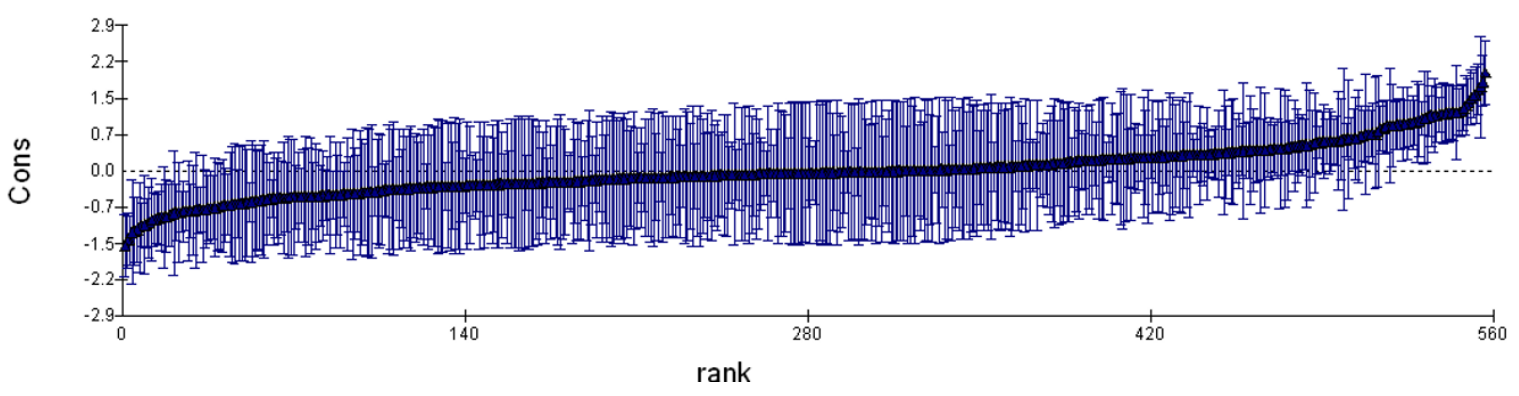

Figure 2 Plasma calcium analyses per physician and HCC in primary care in county of Skaraborg, Sweden. A. percent plasma calcium analyses per physician. B. percent plasma calcium analyses per health care centre (HCC)

by 2.45 times. Including compositional and contextual characteristics in the model did not explain the variance at the higher levels.

Overall 5,8\% of the inhabitants underwent a P-Ca analysis, which is comparable with an earlier study from Skaraborg (6,1\%) [6] and two-fold compared with a study from primary care in southern Stockholm [19] Female patients and patients with previous $\mathrm{P}-\mathrm{Ca}$ analysis were more likely to have a $\mathrm{P}-\mathrm{Ca}$ analysis, which could be explained by women's greater risk of pHPT and recurrent check-ups of patients with chronic diseases.

In order to control for compositional confounding at the patient level we included an individual risk score for $\mathrm{P}-\mathrm{Ca}$-analysis. The inclusion of this variable did not explain the variation between physicians and between HCCs. Further, our empirical analysis found that the sex of the physician had no influence on P-Ca test ordering, in contrast to a study from Israel where female physicians ordered more test [20]. Older and more experienced physicians were less likely to order a P-Ca-test, which is in line with previous studies indicating that test ordering behaviour of GPs was influenced by years of experience [21]. P-Ca analyses done as part of group analyses used in surveillance of different chronic conditions may inflate the number of P-Ca analyses [22]. However, even though the number of group analyses was associated with higher frequency of $\mathrm{P}-\mathrm{Ca}$ analysis, it could not explain the variation at the HCC level.

As explained in previous studies [23]; the measures of variation (e.g. median odds ratio) should be interpreted only for the specific time and place of the study, as there may be pattern of variance produced by different conditions. The associations, however, between characteristics of, on the one hand, the patients, physicians, and HCCs and on the other the frequency of P-Ca analysis, intend to provide information that can be generalised and applied to contexts beyond the one where the study was performed.

The risk for selection bias is low since this study is based on a large sample from a primary care area serving $97 \%$ of the population. Moreover, as this study is a retrospective database study, the ordering of analyses is not influenced by the study. A limitation of the study is that the frequency of ICD coded patient visits varies both between HCCs and according to diagnosis [9]. This might affect the risk score calculation.

Different views of the reason for screening could also affect the result. However national recommendations are well known in Swedish primary care $[1,2]$ thus the risk for bias is minor. Due to regional variation in laboratory testing [8] the results from this study might not be applicable in all regions in Sweden. 
In this study only the variables available in the SPCD database were included. In previous studies, other characteristics of the physician, such as attitude to risk taking and involvement in development of guidelines, explained parts of the higher level variance [8].

We found that there was variation between physicians and between $\mathrm{HCC}$ in ordering of $\mathrm{P}-\mathrm{Ca}$ analysis, which is in line with previous studies [24]. However, in this study we also tried to quantify the contribution of each level by using the median odds ratio. Even though our multilevel approach identified factors, both at the physician and HCC level, which are important to consider for understanding the inclination to order a P-Ca test, none of the included variables could explain the variation at the higher level. The identification of yet unidentified factors that contribute to the variation is needed for monitoring of practice variation and quality assessment and for applying appropriate interventions to achieve optimal frequency of P-Ca analyses.

\section{Conclusions}

National recommendations in Sweden have been issued to increase the frequency of P-Ca analyses to detect more patients with pHPT. There is a substantial variation in number of $\mathrm{P}-\mathrm{Ca}$ analyses primarily between physicians but also between Health Care Centres. Female sex of the patient and increasing number of diagnoses is associated with higher propensity of P-Ca analysis. Physicians under education order most P-Ca analyses and locum least, but sex of the physician has no influence.

\section{Additional material}

\section{Additional file 1 All the variables in the risk score equation. We} selected ICD-10 coded diagnoses and symptoms associated with pHPT. A risk score for a P-Ca analysis was created with stepwise logistic regression based on age, concomitant diagnosis and drug treatment. Total number of patients 154629

\section{Competing interests}

The authors declare that they have no competing interests.

\section{Authors' contributions}

SD conceived the study, drafted the manuscript, responded to the reviewer comments and critically revised the manuscript. PH conceived the study, participated on the design of the study, performed multilevel analyses and interpretation of data responded to the reviewer comments and critically revised the manuscript. $\mathrm{HO}$ participated on the design of the study, supported $\mathrm{PH}$ in the performance of the multilevel analyses and interpretation of data. RE conceived the study and critically revised the manuscript for important intellectual content. JM participated in the design of the study and interpretation of data and critically revised the manuscript for important intellectual content. KBB Conceived the study, drafted the manuscript, responded to the reviewer comments and critically revised the manuscript. All authors read and approved the final manuscript.

\section{Acknowledgement}

This research was funded by Health and Medical Care Executive Board of the Region Västra Götaland, the Swedish Research Council and ALF Government Research Grant. We are most grateful to Birgitta Lindberg for excellent techni- cal assistance in preparation of the manuscript. This paper was presented in part at the Nordic Congresses of General Practice in June 2007.

\section{Author Details}

1 Dept of Public Health and Community Medicine/Primary Health Care, Sahlgrenska academy Gothenburg University, PO Box 454, SE-405 30 Gothenburg, Sweden, 2R\&D Centre Skaraborg Primary Care, Storgatan 18, SE54130 Skövde, Sweden and 3Unit of Social Epidemiology, CRC, Faculty of Medicine, Lund University, Skåne University Hospital, entrance 72, SE-205 05 Malmö, Sweden

Received: 9 November 2009 Accepted: 30 May 2010

Published: 30 May 2010

\section{References}

1. Tryding N: Laborera rätt och lagom i primärvården- klinisk kemi i primärvården (Correct and Optimal use of Clinical Chemistry in Primary Care, English summary). Stockholm: SPRl; 1999.

2. Laborera rätt och lagom - klinisk kemi i primärvården analysdatabasen, (Correct and Optimal use of Clinical Chemistry in Primary Care, English version [http://www3.svls.se/sektioner/sfkk/ nyckel/]

3. Ogard CG, Engholm G, Almdal TP, Vestergaard H: Increased mortality in patients hospitalized with primary hyperparathyroidism during the period 1977-1993 in Denmark. World J Surg 2004, 28:108-111.

4. Nilsson IL, Zedenius J, Yin L, Ekbom A: The association between primary hyperparathyroidism and malignancy: nationwide cohort analysis on cancer incidence after parathyroidectomy. Endocr Relat Cancer 2007 14:135-140.

5. Wermers RA, Khosla S, Atkinson EJ, Grant CS, Hodgson SF, O'Fallon WM, Melton LJ: Survival after the diagnosis of hyperparathyroidism: a population-based study. Am J Med 1998, 104:115-122.

6. Dalemo S, Hjerpe P, Bostrom Bengtsson K: Diagnosis of patients with raised serum calcium level in primary care, Sweden. Scand J Prim Health Care 2006, 24:160-165.

7. Malcolm L, Wright L, Seers M, Davies L, Guthrie J: Laboratory expenditure in Pegasus Medical Group: a comparison of high and low users of laboratory tests with academics. NZMed J 2000, 113:79-81.

8. Verstappen WH, ter Riet G, Dubois WI, Winkens R, Grol RP, Weijden T van der: Variation in test ordering behaviour of GPs: professional or context-related factors? Fam Pract 2004, 21:387-395.

9. Hjerpe P, Merlo J, Ohlsson H, Bengtsson Boström K, Lindblad U: Validity of registration of $I C D$ codes and prescriptions in a research database in Swedish primary care - A cross-sectional study in Skaraborg primary care database. BMC Med Inform Decis Mak 10:23.

10. Bilezikian JP, Brandi ML, Rubin M, Silverberg SJ: Primary hyperparathyroidism: new concepts in clinical, densitometric and biochemical features. J Intern Med 2005, 257:6-17.

11. Merlo J, Gerdtham UG, Eckerlund I, Hakansson S, Otterblad-Olausson P, Pakkanen M, Lindqvist PG: Hospital level of care and neonatal mortality in low- and high-risk deliveries: reassessing the question in Sweden by multilevel analysis. Med Care 2005, 43:1092-1100.

12. Goldstein H: Multilevel Statistical Models. London: Hodder Arnold; 2003.

13. Snijders T, Bosker R: Multilevel Analysis An Intro-duction to Basic and Advanced Multilevel Modeling. London: Sage; 1999.

14. Fielding A, Goldstein H: Cross-classified and Multiple Membership Structures in Multilevel Models: An Introduction and Review. Birmingham: University of Birmingham; 2006.

15. Larsen K, Merlo J: Appropriate assessment of neighborhood effects on individual health: integrating random and fixed effects in multilevel logistic regression. Am J Epidemiol 2005, 161:81-88.

16. Larsen K, Petersen JH, Budtz-Jorgensen E, Endahl L: Interpreting parameters in the logistic regression model with random effects. Biometrics 2000, 56:909-914

17. Gilks WR, Richardson S, Spiegelhalter DJ: Markov Chain Monte Carlo in Pratice. London, Chapman and Hall; 1996.

18. Rasbash JSF, Browne W: A User's Guide to MLwiN, Version 2.0. Documentation Version 2.1e. London: Centre for Multilevel Modelling, Institute of Education, University of London; 2003.

19. Borgquist L, Gustafsson S, Hultén G, Jansson U, Paulsson E, Tryding N: Klinisk kemi i primärvården (Clinical chemistry in primary care, English summary). Stockholm: SPRI; 1996:422. 
20. Vinker S, Kvint I, Erez R, Elhayany A, Kahan E: Effect of the characteristics of family physicians on their utilisation of laboratory tests. Br J Gen Pract 2007, 57:377-382.

21. Salloum S, Franssen E: Laboratory investigations in general practice. Can Fam Physician 1993, 39:1055-1061.

22. Larsson A, Biom S, Wernroth ML, Hulten G, Tryding N: Effects of an education programme to change clinical laboratory testing habits in primary care. Scand J Prim Health Care 1999, 17:238-243.

23. Merlo J, Ohlsson H, Lynch KF, Chaix B, Subramanian S: Individual and collective bodies: using measures of variance and association in contextual epidemiology. Journal of epidemiology and community health 2009 in press

24. Larsson A, Palmer M, Hulten G, Tryding N: Large differences in laboratory utilisation between hospitals in Sweden. Clin Chem Lab Med 2000 38:383-389.

\section{Pre-publication history}

The pre-publication history for this paper can be accessed here: http://www.biomedcentral.com/1471-2296/11/43/prepub

doi: 10.1186/1471-2296-11-43

Cite this article as: Dalemo et al., Variation in plasma calcium analysis in primary care in Sweden - a multilevel analysis BMC Family Practice 2010, 11:43

Submit your next manuscript to BioMed Central and take full advantage of:

- Convenient online submission

- Thorough peer review

- No space constraints or color figure charges

- Immediate publication on acceptance

- Inclusion in PubMed, CAS, Scopus and Google Scholar

- Research which is freely available for redistribution

Submit your manuscript at www.biomedcentral.com/submit
C) Biomed Central 